\title{
Resilience in Mathematics, Academic Resilience, or Mathematical Resilience?: An Overview
}

\author{
Nur Hidayatul Fitrah Binti Ishak*, Nur Fatihah Binti Mat Yusoff, Amalia Madihie \\ Faculty of Cognitive Science and Human Development, University Malaysia Sarawak, Malaysia
}

Received January 22, 2020; Revised April 1, 2020; Accepted April 21, 2020

Copyright $\odot 2020$ by authors, all rights reserved. Authors agree that this article remains permanently open access under the terms of the Creative Commons Attribution License 4.0 International License

\begin{abstract}
Aim: To analyze the concept of resilience in mathematics subject based on three-term use; resilience in mathematics, academics resilience in mathematics, and mathematical resilience. Background: Resilience in academics is a contemporary focus, especially in mathematics subjects. A few terms and concepts of resilience in mathematics subjects introduced, and recently, the term mathematical resilience has received attention and become based on other resilience research in mathematics. Methods: The primary database is Scopus and Google scholar. The keyword use is (a) resilience, resiliences (b) mathematics (c) subjects (d) students, child, adult, to identify the relevant article. Two reviewers are involved in screening and filtering the article in the data extraction process. The screening process is based on the definition, attribute, model use, issue tackle, and approach to tackle the issue. Results: There are 82 articles found both in Scopus and google scholar and Scopus, and 29 were used in the final data analysis. The finding shows that resilience is considered as a personal attribute in a person, which results from the process of adapting to the environment or situation that is challenging. Every term uses a different kind of model to represent resilience but origin from the Bandura Self-Efficiency mechanism. Conclusion: This study provides the meaning of resilience for each term and the differences between them. Even though the world resilience almost similar purpose, the application in each field is different. Future studies should focus on the process and intervention to boost resilience.
\end{abstract}

Keywords Resilience, Academic Resilience, Mathematical Resilience, Mathematics

\section{Introduction}

During these few decades, resilience in academic problems has undergone extensive research. Some researchers focus on specific subjects, some focus on the whole learning life journey. Therefore, many models have been developed to portray resilience in academics. In mathematics subjects, many studies on resilience have been done to prove that resilience is one of the reasons for student success in mathematics. Instead of focusing on the backstory, they try to provide the environment and learning strategy that able to help the student overcome their hardship. The student tends to exhibit bad feeling, especially anxiety when they are working on mathematics problem or attending mathematics class.

Their problem can be detected since kindergarten, especially when the performances are consistently poor (1). While mathematics has imaged as a hard subject, complicated and cause of fear (2), these group of people who has resilience able to overcome it and this draw researcher attention to focus on how the resilience built in them. Many questions revolve, causing this topic to become a depth study. Is resilience a process? Or a personal characteristic? Is resilience is the same for other subjects? Or is there any specific resilience for a specific problem? Do Educational Resilience/Academic Resilience are same with Resilience in Mathematics? Is Mathematical Resilience different from ordinary resilience?

\section{Resilience}

An act to rebounded back after an adverse situation ${ }^{(3)}$ or criteria of a person to display specific positive outcomes after experiencing risk ${ }^{(4,5)}$.According to the dictionary, resilience has two meaning:

I The capacity to recover quickly from difficulties; toughness.

II The ability of a substance or object to spring back into shape; elasticity ${ }^{(6)}$

There have been many studies that try to uncover the 
meaning of resilience. Since early 1970 , people try to describe resilience from a psychology perspective. Bandura's theory on self-efficiency mechanism has become the foundation of the related theory to describe resilience. It is regarding a person's ability on how to react, to thought when facing harsh situations ${ }^{(7)}$. The word resilience when interpreted in psychology perspective, there are three phenomena that they always use is

I Good outcomes despite the high-risk status

II Sustained under threat,

III Recovery from trauma ${ }^{(8)}$

All of the studies that using resilience with a variable coming out with similar finding, which is human has capacities to have protectives factors for development. It can be described either as a process or as an attitude in a person when they face hardship ${ }^{(9)}$. The studies on resilience are always covering this three category which is individual studies (related to trauma and risk recovery), high-risk group (comparing two groups that have a better outcome than other individuals) and ability to adapt despite the stressful situation ${ }^{(10)}$.

Since there are many studies regarding resilience toward mathematics subject, we are going to divide the discussion into three-term

I Resilience in mathematics

II Academic resilience in mathematics

III Mathematical resilience in mathematics.

\section{Resilience in Mathematics}

There have been only a few studies that define the term resilience that relates to mathematics subjects. According to Hernandez-Martinez \& Williams (2013), resilience in mathematics is student reflexivity in making the decision when encountering a new situation. This opinion adapts from the Bourdieu's relational view of social and cultural capital as the capacity for a person to apply agency in a field which is

1. Incorporated in the habitus,

2. Objectified in artefacts or,

3. Institutionalized, ${ }^{(12)}$.

In a study that is using this definition, they interview two students, Jenni and John, in the transition from compulsory school to college and university. Despite coming from a background that does not promote further education, they able to overcome the situation where they undergo a reflective process that allows both of them to adjust to the situation. When an encounter with a problem, John makes self- reflection that makes them conscious of developing institutional capital. He takes full advantage of what is provided and strive better than others. This concludes that mathematics learning requires reflective works and think out of the box ${ }^{(11)}$.

Among 'Black' students, there is a trajectory model composed to represent resilience in them toward mathematics and engineering (figure 1). To understand the coping mechanism in 'Black' student, Mcgee (2009) refers to a PVEST model developed by Spencer (2006). The model starts with an assumption on an individual's perception of their environment and experience that is important in gaining understanding about the Black student response.

Based on the PVEST (figure 2), he comes out with a resilience trajectory is a developmental process that occurred over time. Fragile forms of resilience were dominant during early school experience among the participant; then, over time, robust resilience takes part. High achievement in mathematics that focuses on racial stereotypes is considered a fragile form of resilience. The racial stereotype in social institutions occurs due to historical racism that has been foster for so long ${ }^{(15)}$. This model can explain how the resilience change in students from fragile to robust. 


\section{FRAGILE FORM OF RESILIENCE $\quad$ ROBUST FORM OF RESILIENCE}

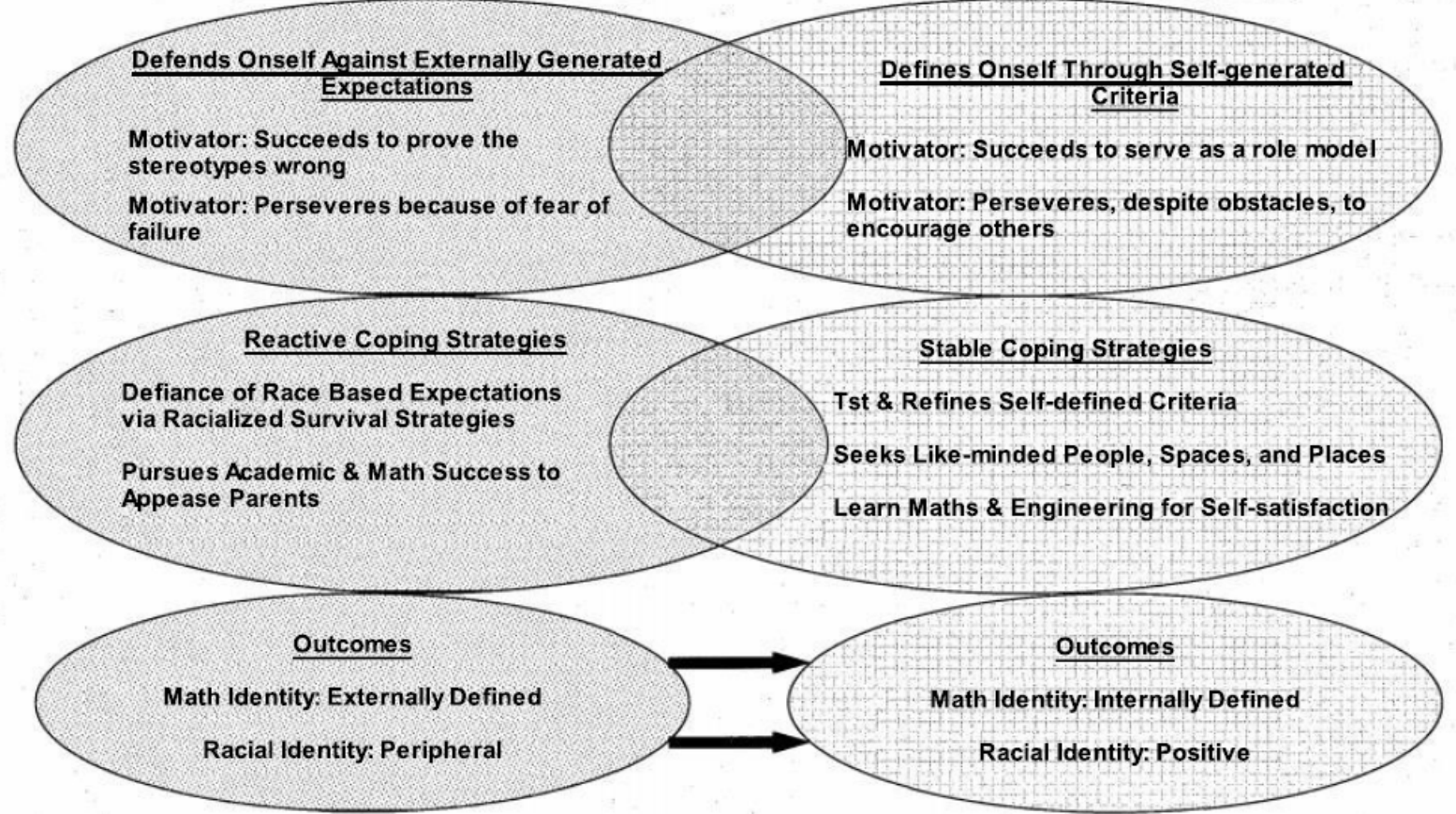

Figure 1. Model for Trajectories of Resilience among Successful Black Mathematics and Engineering Student

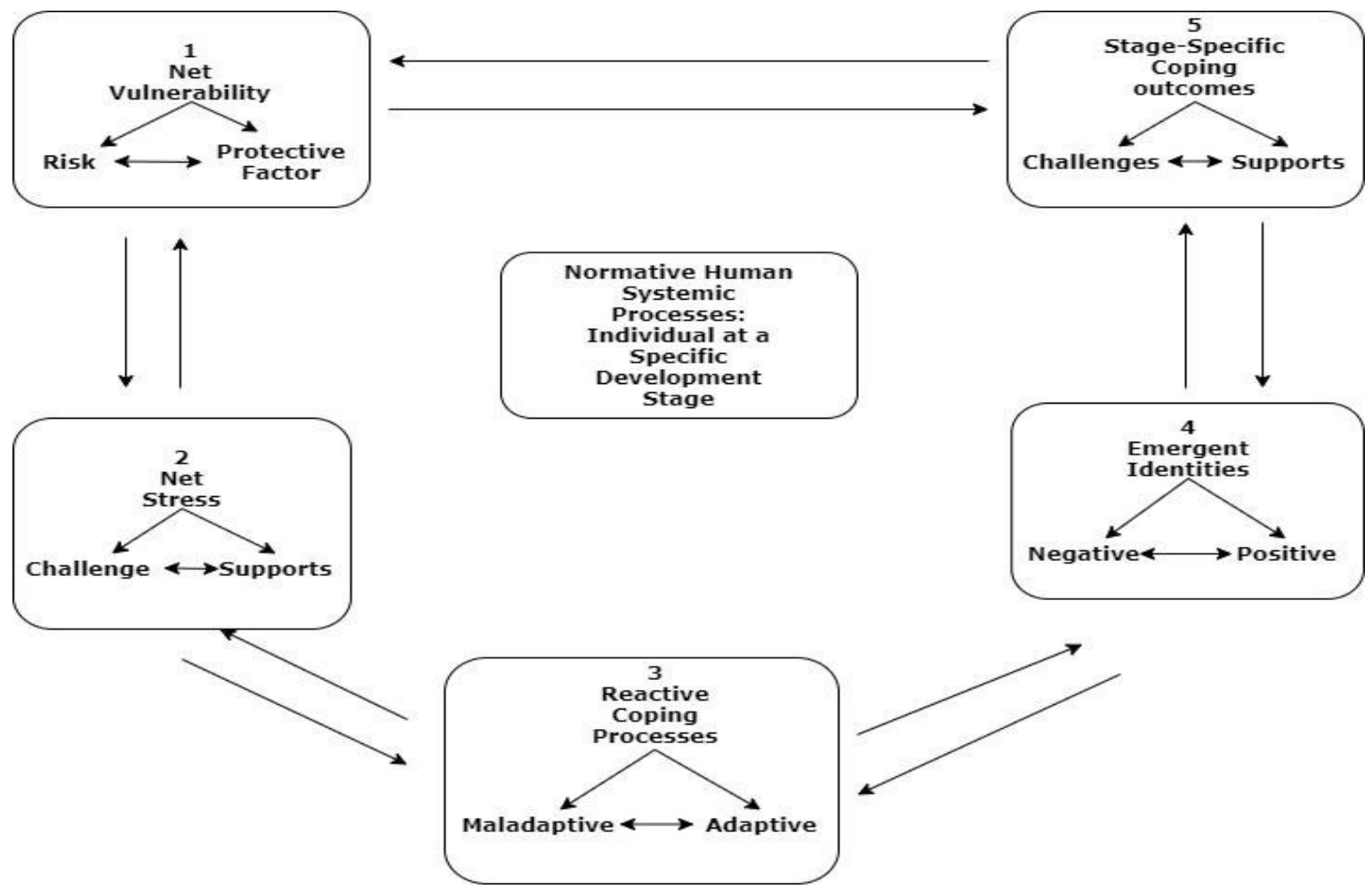

Figure 2. Phenomenological Variant of Ecology Systems Theory (PVEST) 


\section{Academic Resilience in Mathematics}

Academic resilience or educational resilience is defined as "the heightened likelihood of success in school, and other life accomplishments despite environmental adversities brought about by early traits, conditions, and experiences" (Wang, Haertel, \& Walbererg, 1994). It is the student's ability to gain success despite being under depress or harsh situation compared to his other peers. Related to mathematics subject, since many students faced long-tail under-achievement or failure, there are few studies using academic resilience to find out how some students able to gain success despite some obstacles.

A study was done by Borman and Overman (2004) among poor and minority students to understand what is the feature that helps the students become more resilient when learning mathematics subjects. He does not define what resilience concept in his study is; however, the opinion was individual, and school characteristics related to academic risk and resilience, which adapt from Garmezy (1991) that recognized among the high-risk group that encounters some difficulties; many individuals manage to achieve success despite the harsh condition. The resilient in a student can increase or decrease over time, depending on their protective factors ${ }^{(19)}$.

Some of researcher use model to represent academic resilience in mathematics subject the model of Self-Efficacy, Coping Skills and Educational Aspiration (Hope) with antecedent to Bandura social cognitive framework(figure 3) ${ }^{(20)}$. Based on the analysis done Zhaomin, (2014) the result shows that Hope predicts student performances the least, which resulted in overlapping with their coping skills. Coping skills are the latent factors able to measure student performances in mathematics. Family background, cultural, or any risk situation that occurs in student life can be overcome if they have excellent coping skills. This attribute model that has been purposed shows that positive attitude, and their hope gives student power to remain resilient despite the environment adversity.

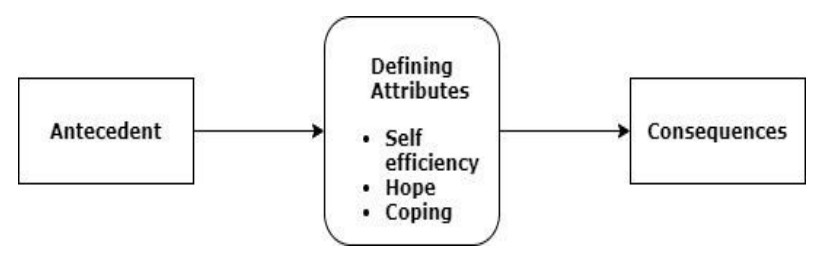

Figure 3. The concept model of resilience ${ }^{(20)}$.

\section{Mathematical Resilience}

The new emerging concept to study resilience in mathematics is mathematical resilience. Since 2008, there have been many papers produce to discuss the use of mathematical resilience. It is an approach that assembles all the support needed to encounter mathematics problems. For many people, mathematics is something that they need to face until the end of school, but many choose to avoid it as soon as school is over ${ }^{(22)}$. There are four aspects of mathematical resilience which are:

- Growth mindset

- The personal value of mathematics

- Knowing that mathematics requires struggle

- And knowing how to find support when pursuing mathematics learning.

This aspect is considered to exist by other researchers such as Bandura (1995) Hernandez-Martinez \& William (2013), Dweck (2000)and Ryan and Deci (2000). When a student exhibits mathematical resilience, he or she will be characterized by a growth mindset. A growth mindset is a belief where with desire and effort, everyone can learn mathematics. It emphasizes the ability of the brain to develop with skills and resilience when the faced problem ${ }^{(26)}$. It is a change from "I cannot" to "I can."

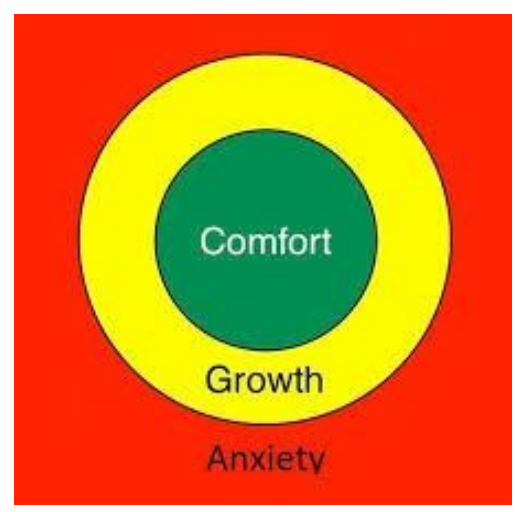

Figure 4. The growth zone model

To change the mindset of a student in learning mathematics can be hard, especially when they already suffer anxiety and learner helplessness. The growth zone model (figure 4) is developed to bring the idea in approaching the mathematical problem which adapts from Vygotsky (1978). This model will enable the learner to understand their feeling when they are working in solving a mathematical problem.

Based on the diagram, there are three zones, which are anxiety or danger zone, growth, and comfort zone.

Anxiety or danger zone: Offline zone where learner encounters bad memories when learning which lead them to feel danger when talking about mathematics

Growth zone: Learner able to learn and progress as more time taken in this zone. They will be challenged to some degree and generate some novel idea.

Comfort zone: Learner will feel comfortable to work with mathematics and develop fluency in this subject ${ }^{(22)}$.

Many studies use mathematical resilience as a measure to understand resilience in mathematics. Since academic resilience is considered in the opposite direction toward learner helplessness, mathematical resilience is a subset of 
the resilience which allows a learner to approach their anxiety and allow them to learn.

The issue that relates to mathematical resilience is mostly related to anxiety and learner helplessness. For example, in their study, stated to overcome repeated failure among students, it is by implementing mathematical resilience in them. This study also has the same concept as a study done by Goodall and Johnston-Wilder (2015). Cropp (2017), in his study, states that mathematic resilience maybe one of the solutions for mathematical anxiety problems. Mathematical anxiety or mathematics anxiety is the feeling of tension and stress when dealing with a number or solving mathematical problems in life ${ }^{(30)}$.

Mathematical resilience can be concluded as a positive stance when learner find mathematics is challenging, and they will find new strategies to overcome it. There are three effective domain to be a resilient mathematical learner which are Value (consider experience learning mathematics is valuable), Struggle (recognize that everyone face hardship with mathematics) and Growth (a belief that all people can develop mathematics skills) ${ }^{(22)}$.

\section{Conclusions}

This overview is done to have a better understanding of how to describe resilience in mathematics. We came up with a table (Table 1) to understand the differences between these three concepts.

The studies on resilience on mathematics subject will keep growing year by year, and this will change the interpretation of the three-term use depend on the direction of the studies done. There are many aspects of resilience that need a precise definition, such as how is resilience describe in developmental psychology, social, and other fields. The only clear definition we have is 'Resilience is an act or behavior or attribute result from adapting adverse situations.' Future study should focus on how the process of resilience happen in a person and also more intervention needed to boost up resilience, especially in mathematics. Since attention on educational psychology rises day by day, there is hope that in the future, there will be a clear border on which concept the researcher will use for the study. We hope this overview will help in understanding the term resilience use relate to mathematics subjects.

Table 1. Differences between 'Resilience, Academic Resilience in Mathematics, and Mathematical Resilience.

\begin{tabular}{|c|c|c|c|}
\hline Concept & Resilience in Mathematics & $\begin{array}{c}\text { Educational/Academic Resilience } \\
\text { in Mathematics }\end{array}$ & Mathematical Resilience \\
\hline Definition & $\begin{array}{l}\text { Behaviour that results from the process } \\
\text { adapting with new situation or risk }\end{array}$ & $\begin{array}{l}\text { An attribute in a person that displays } \\
\text { based on the environment. }\end{array}$ & $\begin{array}{l}\text { Positive stance when a person finds } \\
\text { mathematics is challenging, and they } \\
\text { will find new strategies to overcome it }\end{array}$ \\
\hline $\begin{array}{c}\text { Process / personal } \\
\text { quality }\end{array}$ & Personal quality & Personal quality & Personal quality \\
\hline Model involved & $\begin{array}{ll}\text { - } & \text { Bourdieu \& Passeron } \\
& (1977) \text { : Relational view. } \\
\text { - } & \text { Resilience concept }(31) \\
\text { - } & \text { PVEST }(14)\end{array}$ & $\begin{array}{l}\text { - } \quad \text { Resilience and } \\
\text { Vulnerability (18). } \\
\text { The concept of resilience } \\
\text { (20) }\end{array}$ & Growth mindset theory $(26,27)$ \\
\hline Issues tackle & $\begin{array}{l}\text { - Students at risk (family } \\
\text { background, race, identity, } \\
\text { family income). }\end{array}$ & $\begin{array}{l}\text { - Student at risk (family } \\
\text { background). } \\
\text { - } \quad \text { School environment. }\end{array}$ & $\begin{array}{l}\text { - } \quad \text { Mathematics anxiety. } \\
\text { - } \quad \text { Learner helplessness. }\end{array}$ \\
\hline $\begin{array}{l}\text { Approach to tackle } \\
\text { issue }\end{array}$ & $\begin{array}{l}\text { - Intervention on teaching use } \\
\text { by educators. }\end{array}$ & $\begin{array}{l}\text { Modifying the school } \\
\text { environment from } \\
\text { traditional to a more } \\
\text { communitarian school } \\
\text { model. } \\
\text { Implement good coping } \\
\text { skills. }\end{array}$ & $\begin{array}{l}\text { - } \quad \text { Coaching (for non- } \\
\text { - } \quad \text { Peer mentoring. } \\
\text { - } \quad \text { Problem-based learning. } \\
\text { - } \quad \text { Cognitive behaviour therapy. }\end{array}$ \\
\hline
\end{tabular}




\section{REFERENCES}

[1] Rossnan S. Overcoming math anxiety. Overcoming Math Anxiety. 2006;1(1):1-4.

[2] Johnston-Wilder S, Lee C. Developing Mathematical Resilience. BERA Annu Conf Univ Warwick. 2010;Vol. 4(2):1-11

[3] Masten AS. Global Perspectives on Resilience in Children and Youth. Child Dev. 2014;85(1):6-20.

[4] Luthar SS, Cicchetti D, Becker B. The Construct of Resilience: A Critical Evaluation and Guidance for Future Work. Child Dev. 2000;71(3):543-62.

[5] Masten AS. Ordinary magic: Resilience processes in development. Am Psychol. 2001;56(3):227- 38.

[6] Lexico.com. Resilience [Internet]. Lexico.com. [cited 2019 Nov 12]. Available from: https://www.lexico.com/en/defin ition/resilience

[7] Bandura A. Self-efficacy mechanism in human agency. Am Psychol. 1982;37(2):122-47.

[8] Masten AS, Best KM, Garmezy N. Resilience and development contributions. Dev Psychol. 1991;2(1990):425-44.

[9] Sattler K, Gershoff E. Thresholds of resilience and withinand cross-domain academic achievement among children in poverty. Early Child Res Q [Internet]. 2019;46:87-96. Available from: https://doi.org/10.1016/j.ecresq.2018.04.0 03

[10] Waxman HC, Gray J p., Padron NY. review of research on educational resilience. 2003.

[11] Hernandez-Martinez P, Williams J. Against the odds: Resilience in mathematics students in transition. Br Educ Res J. 2013;39(1):45-59.

[12] Bourdieu P, Passeron J-C. Reproduction in Education, Society and Culture. Vol. 14, Comparative Education. London: Sage publication; 1977. 75-82 p.

[13] Mcgee EO. Race, Identity, and Resilience: Black College Students Negotiating Success in Mathematics and Engineering [Internet]. University of Illinois, Chicago, USA; 2009. Available from: https://eric.ed.gov/?id=ED513184

[14] Spencer MB. Phenomenology and Ecological Systems Theory: Development of Diverse Groups. In: Handbook of child psychology: Theoretical models of human development, Vol 1, 6th ed. Hoboken, NJ, US: John Wiley \& Sons Inc; 2006. p. 829-93.

[15] Steele C. A threat in the air. How stereotypes shape intellectual identity and performance. Am Psychol. 1997;52(6):613-29.

[16] Wang MC, Haertel GD, Walbererg HJ. Educational resilience in inner Cities. Mahwah; 1994.

[17] Borman GD, Overman LT. Academic resilience in mathematics among poor and minority students. Elem Sch J. 2004;104(3):177-95.

[18] Garmezy N. Resiliency and Vulnerability to Adverse Developmental Outcomes Associated With Poverty [Internet]. Vol. 34, American Behavioral Scientist. 1991. p. 416-30. Available from: http://journals.sagepub.com/doi/pdf/10.1177/00027642910 34004003

[19] Henderson N, Milstein MM. Resiliency in schools: Making it happen for students and educators. Thousand Oaks, CA.: Corwin Press; 1996.

[20] Gillespie B, Chaboyer W, Wallis M. Development of a theoretically derived model of resilience through concept analysis. Contemp Nurs. 2007;25(1-2):124-35.

[21] Zhaomin H. Examining the Academic Resilience in Mathematics Performance for the Underprivileged Ninth Graders Using the National Data from the High School Longitudinal Study [Internet]. Texas Tech University, Texas, USA; 2014. Available from: http://hdl.handle.net/2346/58948

[22] Lee C, Johnston-Wilder S. The Construct of Mathematical Resilience. In: Understanding Emotions in Mathematical Thinking and Learning [Internet]. Elsevier Inc.; 2017. p. 269-91. Available from: http://dx.doi.org/10.1016/B978-0-12-802218-4.00010-8

[23] Bandura A. Self-Efficacy in Changing Societies. Cambridge: Cambridge University Press; 1995.

[24] Dweck CS. self-Theories. Philadelphia: Psychology Press Ltd.; 2000. 187 p.

[25] Ryan RM, Deci EL. Self-Determination Theory and the Facilitation of Intrinsic Motivation, Social Development, and Well-Being. Am Psychol. 2000;55(1):68-78.

[26] Yeager DS, Dweck CS. Mindsets That Promote Resilience When Students Believe That Personal Characteristics Can Be Developed. Educ Psychol. 2012;47(4):302-14.

[27] Vygotsky LS. Mind in Society. Cole M, editor. Harvard University Press; 1978. 159p.

[28] Goodall J, Johnston-Wilder S. Overcoming Mathematical Helplessness and Developing Mathematical Resilience in Parents: An Illustrative Case Study. Creat Educ. 2015;06(05):526-35.

[29] Cropp I. Using peer mentoring to reduce mathematical anxiety. Res Pap Educ [Internet]. 2017;1522(May):0. Available from: https://doi.org/10.1080/02671522.2017.13 18808

[30] Richardson FC, Suinn RM. The Mathematics Anxiety Rating Scale: Psychometric data. J Couns Psychol. 1972;19(6):551-4.

[31] Wolff S. The concept of resilience. Aust New Zeal J Psychiatry. 1995;29:256-574. 